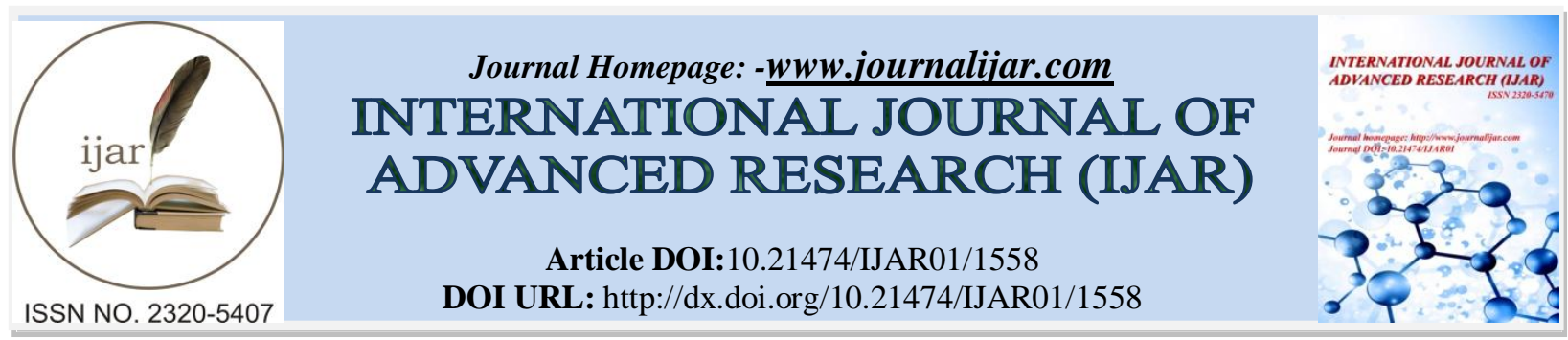

RESEARCH ARTICLE

\title{
A STUDY ON MENSTRUAL KNOWLEDGE AND PRACTICES AMONG RURAL ADOLESCENT GIRLS IN BURDWAN DISTRICT, WESTBENGAL.
}

\author{
Subarna Maji. \\ Research Scholar,Department of Social Work, Visva-Bharati University, Sriniketan, Birbhum District, Westbengal.
}

\section{Manuscript Info}

Manuscript History

Received: 16 July 2016

Final Accepted: 26 August 2016

Published: September 2016

Key words:-

Adolescent girls, Menstruation,

Menstrual Hygiene

\section{Abstract}

Background: Menstruation and menstrual hygiene is one of the important determinants of women's reproductive health but various cultural taboos and socio-cultural restrictions resulting in adolescent girls remaining ignorant of the scientific facts and hygienic health practices, which sometimes result into adverse health outcomes.

Objective:-To study the perception and practices related to menstruation and menstruation hygiene among rural adolescent girls.

Methods:-Adolescent Girls belong to the age group 13-16 years who had menarche for at least one year at the time of study were selected for the study. Data was collected through pre-tested, semi-structured questionnaire through personal interview technique.

Result:-45\% of respondents knew about menstrual cycle before their menarche. In most cases $(60 \%)$ their first informant were their peer group followed by mothers. Most of the girls in the study were not aware of the cause and the source of the bleeding. A majority of them had knowledge about the use of sanitary pads but still now $34 \%$ of them use old cloths and use those cloths. All of them practices one or more cultural taboos and restrictions related to menstruation.

Conclusion:-The knowledge on menstruation among adolescent girls of the study area is poor and the menstrual practices folled by them are unhygienic.So, there is a need to emphasize on menstrual hygiene during policy formulation for adolescents health programmes at community level especially in rural community.

Copy Right, IJAR, 2016,. All rights reserved.

\section{Introduction:-}

Adolescents are a large and growing segment of the world's population. More than half of the world's population is below the age of 25, and one in every two young people in the world is adolescent. Adolescence is a significant period in the life of a woman ( Lawan. UM et al 2010). During adolescence, young people develop their adult identity, move toward physical and psychological maturity. Physiologically, the hypothalamus produces growth hormone and gonadotropins which initiates pubertal changes. Menstruation, the periodic vaginal bleeding that occurs with the shedding of the uterine mucosa is one of the signs of puberty, and occurs one or two years following appearance of secondary sexual characteristics. Once established, every mature female menstruates on the average 3-5 days (minimum 2 days, maximum 7 days) each month until menopause ( Lawan. UM et al 2010).This monthly experience by females adds a powerful tool to the assessment of normal development and the exclusion of

Corresponding Author:-Subarna Maji.

Address:-Research Scholar,Department of Social Work, Visva-Bharati University, Sriniketan, Birbhum 
pathological conditions among them, and it is one of the determinants of a woman's reproductive health (Amaza D et al 2012)

Menstrual hygiene is an issue that is insufficiently acknowledged and has not received adequate attention in the reproductive health and Water, Sanitation and Hygiene (WASH) sectors in developing countries including India and its relationship with and impact on achieving many Millennium Development Goals (MDGs) is rarely acknowledged (Yasmin S et al 2013). Menstruation and menstrual practices are still clouded by taboos and sociocultural restrictions resulting in adolescent girls remaining ignorant of the scientific facts and hygienic health practices, which sometimes result into adverse health outcomes.Menstruation is still regarded as something unclean or dirty in Indian society (Yasmin S et al 2013). Lack of appropriate and sufficient information /awarness regarding menstrual hygiene among adolescent girls may result in incorrect and unhealthy behaviour during their menstrual period. Also, many mothers lack correct information and skills to communicate about menstrual hygiene which they pass on to their children, leading to false attitudes, beliefs and practices among their children. In this regard Menstruation is a phenomenon unique to the females( Lawan. UM et. al 2010). Isolation of the menstruating girls and restrictions being imposed on them in the family, have reinforced a negative attitude towards this phenomenon.

Hygiene related practices of women during menstruation are of considerable importance, especially in terms of increased vulnerability to reproductive tract infections (RTI) (Singh MM et al 2001). Women having better knowledge regarding menstrual hygiene and safe practices are less vulnerable to RTI and its consequences. (Yasmin $\mathrm{S}$ et al 2013). By late adolescence, 75 percent of girls experience some problem associated with menstruation.There are a number of physical, psychological and emotional symptoms that occur premenstrual and during menstruation (Senthil. J et al 2013).As important as menstruation is to human reproduction, it may be accompanied with varying disorders which can affect the quality of life of adolescents and young adult, and can also be indicators of serious reproductive problems (Olowokere. A.E et al 2014).

\section{Objectives:-}

The following are major objectives of the study

1. To assess the perception of menstruation among adolescent girls of the study area.

2. To assess the practices followed during menstruation by adolescent girls of the study area.

3. To highlight the socio-cultural beliefs associated with menstruation

\section{Methodology:-}

A descriptive study design was adopted for the study. The study was conducted among the adolescent girls of Dignagar village, belong to the age group of 13 - 16 yrs. The Dignagar village under Dignagar II GramPanchayat is located in Aushgram I Tehsil of Block of Burdwan Distrct in Wetsbengal. Total no of 100 Sample adolescent girls were selected through purposive sampling method. The inclusion criteria was the adolescent girls belong to the age group 13-16 years who had menarche for at least one year at the time of study. Semi- structured questionnaire was used in the study.The data was collected through the technique of personal interview of the respondents. Data was analysed by Microsoft excel and presented in percentages.

\section{Ethical Consideration:-}

The principles of voluntary participation, anonymity, and confidentiality were strictly followed in the course of this study. Information about the purpose and value of the study were provided to each participants. As the study is on very sensitive issue, informed consent was obtained from each participant and their mothers.

\section{Results:-}

\section{Respondents' Socio-demographic information:-}

Table 1 showed that in the study that age of the respondents $(n=100)$ varied from $13-16$ years. Most of the respondents were between the age bracket of 15 to 16 years with a percentage of 44 . The study population were mainly Hindu (73\%) and belong to nuclear family (80\%). Education of their mothers are mostly upto primary level which was $42 \%$, madhyamik was $27 \%$, higher-secondary was only $21 \%$ and illiterate was $10 \%$. It was observed that $58 \%$ of respondent's father were farmer, $29 \%$ were daily labour and only $10 \%$ were govt. employee. Most of the respondent's mother were housewives (60\%) and $17 \%$ of respondent's mother worked as domestic workers and $23 \%$ were daily labour. 


\section{Respondents' knowledge of menstruation and menstrual hygiene:-}

Table 2 showed $77 \%$ ofrespondents knew about menstrual cycle before their menarche. In most cases (43\%) their first informant were their peer group followed by their mother. Only $16 \%$ girls have correct information the organ from where bleeding occurs that is uterus instead of vagina . 38\% of the respondentscorrectly knew that menstruation is normal and it is natural or physiological process but still in $21^{\text {st }}$ century $16 \%$ of them belive that it is god given and sometimes a curse also.88\% of the respondents knew that the duration of a normal menses is 2 to 7 days. Most of the respondents (98.0\%) knew that sanitary products are available for menstrual protection and sanitary pad is the best sanitary absorbent recommended for adolescents. It may be the result of various mass media specially T.V.67\% of them were unaware about harmful effects of poor menstrual hygiene which can cause infections and maintaing proper menstrual can be the prevention of menstrual pain and other diseases like Reproductive Tract Infections and Sexually Transmitted Diseases.

\section{Respondents' practices regarding menstrual hygiene:-}

Around 59.0\% of girls mentioned that menstruation begins between the ages of 12-13 years. 68\% used sanitary pad only. Though $66 \%$ of the respondants use sanitary pad but still $34 \%$ use old clothts and most of them reuse those cloths. They also faced problem in maintaing privacy while washing and drying of those cloths. As a result of privacy problem they dry and store those cloths in unhygeinic places which sometimes causes infections . $75 \%$ of adolescent girls said that they were disposing the used pads in ponds and 33\% of them were disposing with usual home garbage $2 \%$ of them burn those used pads. Only $22 \%$ of them change of sanitary pads twice every 24 hours and rest of them change once every 24 hours or according to situation. Daily bath was restricted upto three days because of cultural taboos as bathing increases the menstrual flow. Only $10 \%$ of respondants bath daily though it is a good mentrual hygiene practice. None of the respondants used feminine wash but $36 \%$ girls used ordinary soap and water to clean their genitalia . $37 \%$ of respondents did not washproperly their hands after using sanitary napkins and every time after toilet during menstruation . $44 \%$ and $29 \%$ of respondants respectivelyupset and tensed during their first menstruation. All the respondants practiced all or any of those practices showed in table 3. Among them, all girls did not attend any religious functions or visit temples, $57 \%$ girls were not allowed to touched stored foods, $97 \%$ girls were taking bath on fourth day of menstruation, $74 \%$ girls were not allowed to touch plants during menstruation.

\section{Discussion:-}

Menstruation is a natural and physiological phenomenon in a female who has reached the age of puberty. Lack of knowledge and poor personal hygienic practices during menstruation can lead to various gynecological problems in the reproductive life of girls (Kamath $\mathrm{R}$ et al 2013). In the present study, though most of the adolescent girls aware about the fact of age of menarche, length of the menstrual cycle, and duration of menstrual bleeding, use of sanitary pads only few percentages $(16.0 \%)$ of them know that menstruation occurs through the uterus. $62 \%$ of them were unaware regarding the reason for menstruation. Similar studies also revealed similar findings like (Khan, 2012); (72\%), (Thakre SB et al 2011) (80\%). But the findings of this study contradicts the study of (Drakshayani et al 1994), detected that around $78.5 \%$ knew menstrual bleeding originated from the uterus. There is gap in educational system where reproductive health is not taught because either considered non important or unsocial. It is assumed that knowledge regarding menstruation will come gradually by its own. The main source of knowledge regarding menstruation was peer group (43\%), followed by mother (35\%) which contradicts the findings of(Munday.A.B, et al2010) and (Barathalakshmi, 2014) where mother was the main source of knowledge and study of Egypt by (ElGilany AH \& Badawi K. , 2005) where mass media were the main source of information about menstrual hygiene, followed by mothers.Maximum no of adolescent girls had menarche between 12to 14yrs with maximum in 13th year which is comparable to (Thakre SB, et al2011).In the present study, the mean age of menarche of the respondents was 12.94 years, whereas in a study conducted in Rajasthan in 2005 by Khanna et al the mean age at menarche was found to be 13.2 years. (Khanna A, Goyal RS, Bhawsar R., 2005).The hygiene related practices of women during menstruation are of considerable importance, as they affect their health by increasing their vulnerability to infections, especially infections of the urinary tract and the perineum. In present study $66 \%$ girls used sanitary pads. More than $90 \%$ adolscents girls were either throwing used pad, wrapping it in paper, in pond or dutbin which is comparable to the results of ( (Dasgupta A \& Sarkar M, 2008;). Though majority of girls in this study, used sanitary pads, a considerable number of them (34\%)use old cloths as aborbents and $90 \%$ of them reused old cloths after washingas compared to the study of ((Munday.AB, et al 2010).In West Bengal, majority of girls preferred cloth pieces rather than sanitary pads as menstrual absorbent. (Dasgupta A \& Sarkar M, 2008;) The reason may their inability to afford sanitary pads because of their lower economical background. Sanitary napkins (pads) should be changed as often as necessary, before the pad is soaked with menstrual flow. There is a risk of Toxic Shock Syndrome by using super absorbency materials. But only $22 \%$ of them change absorbents twice in 24 hours. The 
place of storage of the pads/ napkins is equally important for their cleanliness but most of the girls usually dried washed cloths and stored them in unhygienic places away from prying eyes which could give rise to the harboring of dust and insects. Cleanliness of external genitalia is also playing major role in prevention of Reproductive tract infections. In present study only $10 \%$ bath daily during menstruation, $36 \%$ adolescent were using soap and water to clean external genitalia. The reasons may be their lack of knowledge about menstrual hygiene and privacy. The similar studies of (Munday.AB, et al 2010) (Omidwar S, \& Begum K., 2010) reveals similar findings. 73\% girls in present study felt either tensed or upset during their menstruation which is similar to the study done by Abraham et al cited by (Rumunet al2014) among the Australian women revealed that a high proportion (80\%) considered menstruation to be inconvenient or embarrassing. Present studies revealed different types of restrictions which were practiced during menstruation in the study area. All of the respondents followed some restriction or taboo related to food or religious rituals, touching plants, taking shower etc and avoid religious work, entering temples during menstruation.These findings were consistent with those of other studies (Munday.AB, et al 2010) (Thakre SB,et al 2011)(Dasgupta A and Sarkar M., 2008)

\section{Conclusion:-}

The study reveals the fact that among the adolescent girls of the study area, the knowledge on menstruation is poor and the menstruation practices are often unhygiene. Menstruation cycle and menstrual hygiene is one of the important aspect of Reproductive Health which is a crucial part of general health and central feature of human development. It is of special concern for women particularly during reproductive years. Failure to deal with the reproductive problems at any stage in life sets severe effect for late health and developmental pattern. The study findings shows that there is the need to encourage safe and hygienic practices among the rural adolescent girls and bring them out of traditional beliefs, misconceptions and restrictions regarding menstruation. Information is power, and knowledge is well known to influence attitude over time. So, it is imporatant to work both the Government (community health functionaries like ASHA, AWW) as well as the Non- Government Organizations to adress this issues and work paralally to develop awarness among both parents and the adolescents on the unmet needs of adolescents including sexuality education. Menstrual hygiene promotion needs to be included in school curriculum. The Social workers should be involved in school health progrogrammes to break the cultural silence on Menstrual issues and impart scientic knowledge on menstrual hygiene to help the adolescent girls to cope with menstruation related problems as well as reproductive health problems.

\section{Acknowledgement:-}

Author would like to express her sincere gratitude to all those who have in some way contributed in this study. She would like to thanks all the adolescent girlswho participatewith all enthusiasm. She is very much thankful to the mothers of participant girls and Gram panchyat members for their support to run this study smoothly.

Table 1:-Distribution of respondents according to their socio-demographic information $(n=100)$

\begin{tabular}{|c|c|c|}
\hline Variables & Frequency & Percent (\%) \\
\hline Age & & \\
\hline $12-13$ & 15 & $15.00 \%$ \\
\hline $13-14$ & 22 & $22.00 \%$ \\
\hline $14-15$ & 19 & $44.00 \%$ \\
\hline $15-16$ & 44 & \\
\hline Religion & & $80.00 \%$ \\
\hline Hindu & 73 & $20.00 \%$ \\
\hline Muslim & 27 & \\
\hline Family Structure & & $80 \%$ \\
\hline Nuclear & 80 & $20 \%$ \\
\hline Joint & 20 & $10 \%$ \\
\hline Education of Mothers & & $42 \%$ \\
\hline Illiterate & 10 & $27 \%$ \\
\hline Primary level & 42 & $21 \%$ \\
\hline Madhyamik & 27 & \\
\hline Higher Secondary & 21 & $29 \%$ \\
\hline Occupation of Father & & \\
\hline Daily labour & 29 & \\
\hline
\end{tabular}




\begin{tabular}{|c|c|c|}
\hline Farmer & 58 & $58 \%$ \\
\hline Business man & 3 & $3 \%$ \\
\hline Govt Employee & 10 & $10 \%$ \\
\hline Occupation of Mother & & \\
\hline Housewife & 60 & $60 \%$ \\
\hline Daily labour & 23 & $23 \%$ \\
\hline Domestic worker & 17 & $17 \%$ \\
\hline
\end{tabular}

Source: Primary data

Table 2:-Distribution of respondents according to their Knowledge about menstruation $(n=100)$

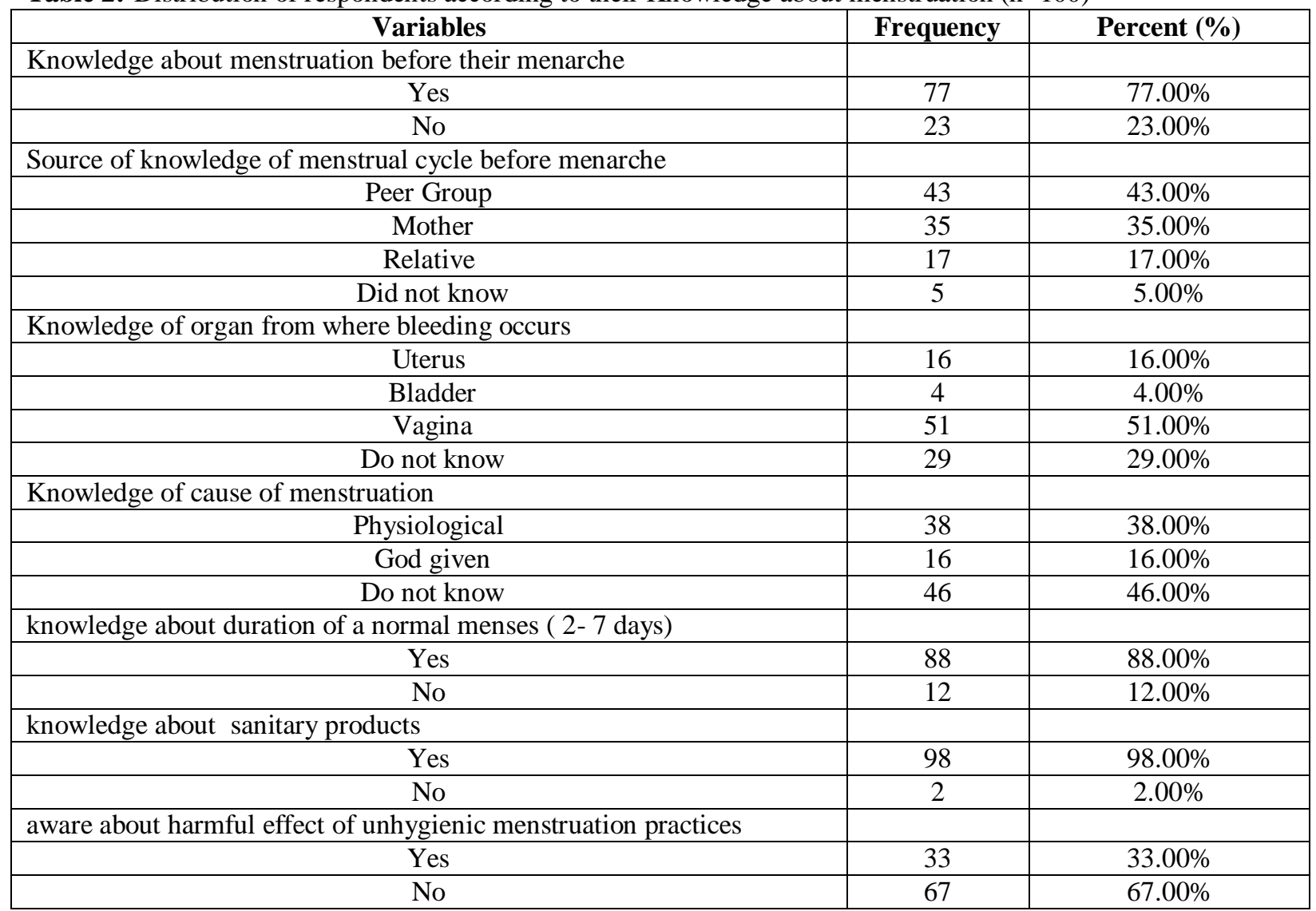

Source: Primary data

Table 3:- Distribution of respondents according to their Knowledge hygienic practices during menstruation $(\mathrm{n}=100$

\begin{tabular}{|c|c|c|}
\hline Variables & Frequency & Percent (\%) \\
\hline Age at menarche & & \\
\hline $10-12$ & 22 & $22.00 \%$ \\
\hline $12-14$ & 59 & $59.00 \%$ \\
\hline 14-16 & 19 & $19.00 \%$ \\
\hline Oype of absorbents use cloths & 34 & $34.00 \%$ \\
\hline Sanitary napkin & 66 & $66.00 \%$ \\
\hline other specific & 0 & $0.00 \%$ \\
\hline Change of absorbents & 22 & $22.00 \%$ \\
\hline twice every 24 hours & 30 & $30.00 \%$ \\
\hline once every 24 hours & 48 & $48.00 \%$ \\
\hline depends on situation & & \\
\hline Reuse the absorbents &
\end{tabular}




\begin{tabular}{|c|c|c|}
\hline Yes & 90 & $90.00 \%$ \\
\hline No & 10 & $10.00 \%$ \\
\hline \multicolumn{3}{|l|}{ Disposal of the pad } \\
\hline Pond & 75 & $75.00 \%$ \\
\hline Dustbin & 23 & $23.00 \%$ \\
\hline Burn & 2 & $2.00 \%$ \\
\hline \multicolumn{3}{|l|}{ Bath during period } \\
\hline First day & 28 & $28.00 \%$ \\
\hline fourth day & 62 & $62.00 \%$ \\
\hline Daily & 10 & $10.00 \%$ \\
\hline \multicolumn{3}{|c|}{$\begin{array}{l}\text { wash hands after using sanitary napkins and every time after } \\
\text { toilet during menstruation }\end{array}$} \\
\hline Yes & 63 & $63.00 \%$ \\
\hline No & 37 & $37.00 \%$ \\
\hline \multicolumn{3}{|l|}{ Material use for cleaning purpose } \\
\hline Plain Water & 64 & $64.00 \%$ \\
\hline Soap + Water & 36 & $36.00 \%$ \\
\hline Feminine Wash & 0 & $0.00 \%$ \\
\hline \multicolumn{3}{|l|}{ Menstruation for the first time } \\
\hline Normal & 27 & $27.00 \%$ \\
\hline Upset & 44 & $44.00 \%$ \\
\hline Tensed & 29 & $29.00 \%$ \\
\hline \multicolumn{3}{|c|}{$\begin{array}{l}\text { Different restriction among adolescent girls during } \\
\text { menstruation }\end{array}$} \\
\hline Touch foods & 57 & $57.00 \%$ \\
\hline Religious place & 100 & $100.00 \%$ \\
\hline Taking bath on fourth day of menstruation & 67 & $67.00 \%$ \\
\hline Touch plants & 74 & $74.00 \%$ \\
\hline
\end{tabular}

Source: Primary data

\section{References:-}

1. Amaza D, Sambo N, Zirahei J, Dalori M, Japhet H and Toyin H. (2012). Menstrual Pattern among Female Medical Students in University of Maiduguri, Nigeria. British Journal of Medicine \& Medical Research, 2(3), 327-337.

2. Barathalakshmi, j. (2014). Knowledge and Practice of Menstrual Hygiene among School Going Adolescent Girls. National Journal of Research in Community Medicine, 2, 138-142.

3. Dasgupta A \& Sarkar M. (2008;). How hygienic is the adolescent girl? IJCM, 32(2), 77-80.

4. Dasgupta A and Sarkar M. (2008). Menstrual hygiene: How hygienic is the adolescent girl? Indian Journal of Community Medicine, 33, 77-80.

5. Drakshayani Devi K, Venkata Ramaiah P.A. (1994). study on menstrual hygiene among rural adolescent girls. Indian J Med Sci, 48(6), 139-43.

6. El-Gilany AH \& Badawi K. . (2005). Menstrual hygiene among adolescent schoolgirls in Mansoura, Egypt. Reprod Health Matters, 13, 147-152.

7. Kamath R, Ghosh D, Lena A and Chandrasekaran. (2013). A Study On Knowledge And Practices Regarding Menstrual Hygiene Among Rural And Urban Adolescent Girls In Udupi Taluk, Manipal, India. Global Journal of Medicine and Public Health, 2(4).

8. Khan, A. .. (2012). Perceptions and practices about menstrual hygiene among adolescent girls in a rural area - a cross-sectional study. Int J Health Sci Res, 2(8), 29-34.

9. Khanna A, Goyal RS, Bhawsar R. (2005). Menstrual practices and reproductive problems: a study of adolescent girls in Rajasthan. $J$ Health Manag, 7, 91-107.

10. Lawan. UM , Yusuf N W, and Musa. A.B. (2010). Menstruation and Menstrual Hygiene amongst Adolescent School Girls in Kano, Northwestern Nigeria . African Journal of Reproductive Health, 14(3), 201-207. 
11. Munday.AB,Keshwani N, Mudey GA, Goyal RC. (2010). A Cross-sectional Study on Awareness Regarding Safe and hygienic Practices amongst School Going Adolescent Girls in Rural Area of Wardha District, India. Global Journal of Health Science, 2(2), 225-231.

12. Olowokere. A.E, Monisola O. Oginni, Aanuoluwapo O Olajubu, Augusta E. William, Omolola O. Irinoye. (2014). Menstrual disorders: The implications on health and academic activities of female undergraduates in a federal university in Nigeria. Journal of Nursing Education and Practice, 4(5), 126-135.

13. Omidwar S, \& Begum K. (2010). Factors which influence the hygienic practices during menses among girls from south India: A cross sectional study. International Journal of Collaborative Research on Internal Medicine and Public Health, 2, 411-423.

14. Rumun, Akpenpuun Joyce \& Azende Peter Msuega. (2014). Menstrual Knowledge And Practices Among Adolescent Females In Makurdi Metropolis. Global Journal of Interdisciplined Social Sciences, 3(3), 113-121 .

15. Senthil. j ,T. Pugalenthi, K. K. Jayakumar and C. Pandiammal. (2013). Determinants of menstrual hygiene practice among unmarried women in India. Archives of Applied Science Research, 5(4), 137-145.

16. Singh MM,Devi R, Garg S and Mehra M. (2001). Effectiveness of syndromic approach in management of reproductive tract infections in women. Indian Journal of Medical Science, 55(4), 209-214.

17. Sudeshna R and Dasgupta A. (2012). Determinants of menstrual hygiene among adolescent girls: a multivariate analysis. National Journal of Community Medicine, 3, 294-301.

18. Thakre SB, Thakre SS, Reddy M, Rathi N, Pathak K., Ughade S. (2011). Menstrual Hygiene: Knowledge and Practice among Adolescent School Girls of Saoner, Nagpur District. Journal of Clinical and Diagnostic Research, 5(5), 1027-1033.

19. UNICEF. (2008). Sharing simple facts: useful information about menstrual health and hygiene. New Delhi, India: Child's Environment Section, UNICEF House.

20. Yasmin. S, Manna N, Mallik S, Ahmed A and Paria B. (2013). Menstrual hygiene among adolescent school students: An indepth cross-sectional study in an urban community of WestBengal, India. Journal of Dental and Medical Sciences, 5( 6), 22-26. 